\title{
A study of the reptile populations in the Shielhill Glen, Clyde Muirshiel Regional Park, Scotland
}

\author{
K. McMillan \\ Greenock Cut Visitor Centre, Clyde Muirshiel Regional Park PA16 9LX \\ E-mail: Kathleenmcm07@yahoo.co.uk
}

\section{INTRODUCTION}

Scotland is home to three of Britain's native reptiles that have evolved to live in cooler climates: the common lizard (Zootoca vivipara), the slow-worm (Anguis fragilis) and the European adder (Vipera berus) (McInerny \& Minting, 2016). Clyde Muirshiel Regional Park covers ca. $280 \mathrm{~km}^{2}$ in the central lowlands on the west coast of Scotland, with habitats that appear suitable for reptiles. However, the species present and their numbers have not been established. Survey work, described here, showed that habitat Shielhill Glen, near the Greenock Cut Visitor Centre, encompassing both moorland and improved grassland, supports a population of common lizards, but slow-worms and adders were not detected.

\section{METHODS}

The study took place in Shielhill Glen, near the Greenock Cut Visitor Centre. A nature trail with a 45minute circular walking path runs through the glen. The trail's boardwalk is a key feature of the study as it provides sites for basking reptiles.

The habitat in the glen around the boardwalk consists of a mosaic of different vegetation types: heather (Calluna vulgaris) and grazed open grassland, interspersed with areas of gorse (Ulex europaeus) and bracken (Pteridium spp.). On the north side of the glen is a Site of Special Scientific Interest (SSSI) of natural regenerating woodland.

Another key feature of the study area in the glen is a stone wall, which acts as a barrier for the sheep farmed on the moorland to prevent them from entering the SSSI. Because of their grazing patterns, the sheep control the growth of new plants and the height of existing plants.

The Shielhill Glen study area, comprising 15.1 ha, has five habitats that have the potential to support reptile populations. All are interconnected, some sharing ecotones or the stone wall. These habitats are: Habitat 1 - open grassland; Habitat 2 - heather (Calluna vulgaris) and moorland grasses; Habitat 3 gorse (Ulex spp.); Habitat 4 - bracken (Pteridium spp.); and Habitat 5 - stone wall and SSSI.
Fifty artificial refugia, made from black roofing felts $50 \mathrm{~cm} \times 50 \mathrm{~cm}$ in size, were placed in suitable locations, with ten in each of the five habitats areas. The felts were numbered and their locations recorded using global positioning system (GPS). Four corrugated iron "tins" were also placed in Habitat 1. Both materials were used to target different reptiles; adders prefer corrugated iron, whereas roofing felts are preferred by lizards (Langham, 2011). Published reptile survey methods were followed (Froglife, 1999).

The felts were inspected when weather conditions were suitable for locating reptiles: an air temperature $8-20^{\circ} \mathrm{C}$, dry, with open cloud cover to allow the heat from the sun to reach the ground. Surveys times were influenced by weather conditions from 10 a.m. to 7 p.m. Air temperature was taken from the weather station at the Greenock Cut Visitor Centre at the start of each survey. The duration of each survey was recorded. At each felt the number of reptiles above and below was recorded, along with those seen in the surrounding vegetation, or on the adjacent walls or boardwalk.

\section{RESULTS}

Over four months, from June to September 2013, 46 survey days were completed. Only one native reptile species was recorded, with 150 sightings of the common lizard. No slow-worms or adders were found.

\section{Lizard numbers}

Lizard numbers were recorded as follows: 1) total number seen (all locations: felts, boardwalk, undergrowth); 2) number seen using the felts, both on top and under the felts; 3 ) number seen on top of felts; 4) number seen under felts; and 5) reptiles seen near the felt using the boardwalk, stone wall or undergrowth.

In total, 150 lizards were recorded. Of these 109 were found using felts, and 41 in other locations, including the stone wall, boardwalk and undergrowth. Out of the 109 reptiles using felts, only 66 were seen on felts with 43 under felts. 
Eight surveys were carried out during June, with a total of ten reptiles being seen through the month (average of 1.25 lizards per survey). In July the number of surveys increased to 14 due to improved weather. As a result, the total number of reptiles seen rose to 20 (1.43 lizards per survey). During August 16 surveys took place with a total of 96 reptiles recorded (6.00 lizards per survey). This was due to weather conditions; also August is when young lizards are born. In September the number of reptiles seen was 24 , over seven surveys (3.43 lizards per survey).

\section{Lizard habitats}

Habitat 1, open grassland

No reptiles were found. This area was grazed by sheep with the vegetation controlled, and no new growth.

\section{Habitat 2, heather moorland}

Thirty-two lizards were observed. Within this habitat, lizards were only found using felts, even though alternative basking sites were present.

\section{Habitat 3, gorse}

Twenty-three lizards were observed, in all five locations; 22 used felts, with only one lizard seen in another location.

\section{Habitat 4, bracken}

Fourteen lizards were observed, in all five locations. Of these, nine lizards used felts. The lower number of lizards within this habitat could be a result of the bracken covering basking sites.

Habitat 5, stone wall and SSSI

Eighty-one lizards were observed, the highest recorded, with 46 of these using felts.

\section{DISCUSSION}

Certain landscape features are important for reptiles and are referred to as "key features" (Bray et al., 1997). These key features should be taken into consideration in management plans in areas where reptiles are present. The Shielhill Glen has many key landscape features for reptiles. However, only one species was found, the common lizard. A number of different habitats at the site were identified as supporting lizard populations: heather moorland, gorse and bracken, with the main population at a stone wall and SSSI.

It is unclear why adders or slow-worms were not found within the area. Studying other locations around the Greenock Cut Visitor Centre might reveal these two species. However, it is possible that none was found because they are absent. This could be due to the habitat being unsuitable, or the extinction of populations. Alternatively, the surveys may not have located the species, being at the incorrect time of the day and/or year. The surveys described here were conducted from 10 a.m. to 7 p.m. during June to
September. In contrast, surveys for adders and slowworms elsewhere in west Scotland have revealed highest numbers of both reptiles, monitoring from 8 - 10 a.m. during February to April (McInerny, 2017).

\section{REFERENCES}

Bray, R. \& Gent, T. (Editors) (1997). Opportunities for Amphibians and Reptiles in the Designed Landscape. English Nature Science Series No. 30. English Nature, Peterborough.

Clyde Amphibian and Reptile Group (2018). http://c-arg.webnode.com/about-us/

Froglife (1999). Reptile Survey: An Introduction to Planning, Conducting and Interpreting Surveys for Snake and Lizard Conservation. Froglife Advice Sheet 10. Froglife, Halesworth. http://www.froglife.org/wpcontent/uploads/2014/01/FAS_10.pdf

Langham. S. (2011). SARG Specification for Reptile Survey Refugia. Surrey Amphibian and Reptile Group.

http://surrey-arg.org.uk/SARG/07000-

Publications/Guides/SARG

RefugiaSpecification.pdf

McInerny C.J. (2017). Observations on co-existing populations of adders, slow-worms and common lizards at Loch Lomond, Scotland: implications for conservation. The Glasgow Naturalist 26(3): 15-24.

McInerny, C.J. \& Minting, P. (2016). The Amphibians and Reptiles of Scotland. Glasgow Natural History Society, Glasgow.

SNH. (2018). Protected Species - Amphibians and Reptiles (2018).

http://www.snh.gov.uk/protecting-scotlandsnature/protected-species/which-andhow/amphibians-reptiles/

Sewell, D., Griffiths, R.A., Beebee, T.J.C., Foster J. \& Wilkinson, J.W. (2013). Survey Protocols for the British Herpetofauna. Version 1.0. http://www.narrs.org.uk/documents/Survey_pr otocols_for_the_British_herpetofauna.pdf

Natural England. (2018). Standing Advice Species Sheet: Reptiles. http://www.naturalengland.org.uk/Images/Rep tiles_tcm6-21712.pdf 